\title{
The Expression of Caveolin by HDL in Cholesterol-Loaded Aortic Endothelial Cells
}

\author{
W. T. Chao* and V. C. Yang* \\ * Department of Biology, Tunghai University, 181, 3rd Section, Chung-Kang Rd. 407. Taichung, \\ Taiwan. R. O. C.
}

It has been demonstrated that the high-density lipoprotein (HDL) has the atheroprotective effect because of its involvement in the reverse cholesterol transport.[1] However there is considerable debate about the mechanisms by which HDL removes excess cholesterol from cells. Two different $p$ athways have been suggested: $(\quad$ i) a docking receptor promotes cholesterol translocation, or ( $\quad$ ii) a receptor mediates intracellular endosomal pathway termed " retroendocytosis". The non -coated vesicular invaginations structur e " caveolae" was recognized as flask-shaped indentations of the cell membrane half a century ago, and caveolin is the main structural protein of caveolae.[ 2] The caveolae play an important role in cellular cholesterol trafficking and facilitating the trans fer of free cholesterol and cholesterol ester into and out of the cell, but the effects of the HDL on caveolae have not yet been reported. In order to investigate the expression pattern of caveolin in HDL -mediated cholesterol efflux, the aortic endothelial cells were first loaded with cholesterol for $24 \mathrm{hr}$ and $48 \mathrm{hr}$ and followed by incubation with HDL for $5 \mathrm{~min}, 15 \mathrm{~min}, 1 \mathrm{~h}, 2 \mathrm{~h}$, and $3 \mathrm{~h}$. The expression of caveolin and the localization of caveolae and HDL in the cell were performed by Western blot and immunocytochemistry.

The preliminary result s showed that when cells were incubated with HDL at $5 \mathrm{~min}$, the HDL were colocalized with caveolae which are concentrated in the central region of the cytoplasm. At $15 \mathrm{~min}$, the HDL and caveolae appeared in the peripheral region of the cell. Western blot analysis showed that the expression of caveolin significantly increased at $24 \mathrm{~h}$ and $48 \mathrm{~h}$ after cholesterol loading. When the cholesterol-loaded cells were incubated with HDL, the expression of caveolin decreased at $1 \mathrm{hr}$, an $\mathrm{d}$ increased again at $3 \mathrm{~h}$. From this preliminary results, we assume that the caveolin expression related to cholesterol loading as well as the HDL-mediated cholesterol efflux in the endothelial cells. Whether the HDL enters into the cells by the plasmalemmal vesicles and transport the excess cholesterol back to cell surface by retroendocytosis or HDL just colocalize with caveolae in the membrane invagination to promote the cholesterol translocation, further experiments need to be done.

\section{References}

[1] A. R. Tall, Eur. Heart J. 19 (1998) A31-A35.

[2] C. J. Fielding, and P. E. Fielding, Biochim. Biophys. Acta. 1529 (2000) 210-222. 

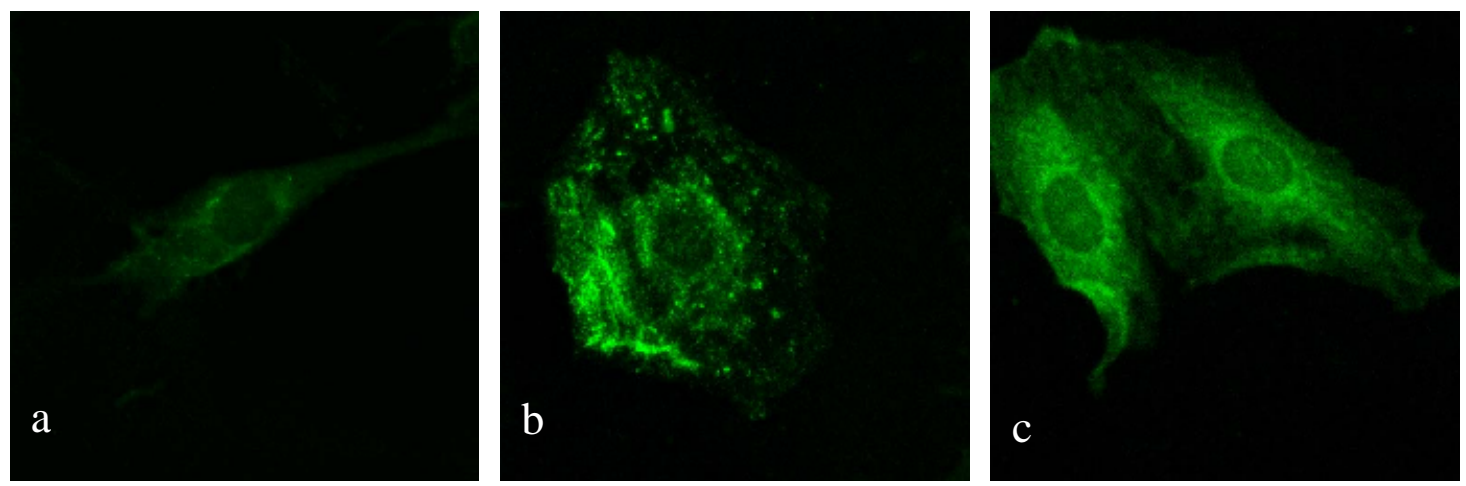

FIG. 1. The caveolin was observed in rat aortic endothelial cells growing in the culture medium without cholesterol loading (a). At $24 \mathrm{~h}$ after cholesterol loading, most of the caveolins was revealed predominantly in the cell membrane domain (b). At $48 \mathrm{~h}$, the caveolin was also detected in the cytoplasm of the cell (c).
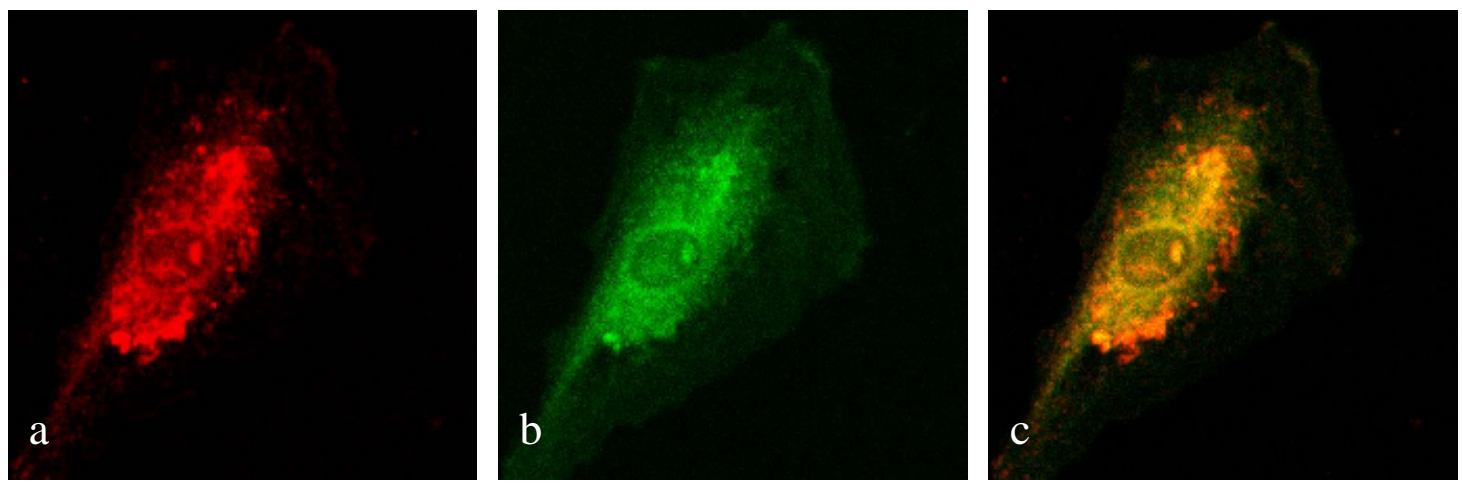

FIG. 2. When cholesterol-loaded cells were incubated with HDL for $5 \mathrm{~min}$, the HDL (a) and caveolin (b) were revealed in the cytoplasm. The HDL and caveolin colocalized in the cytoplasm (c).

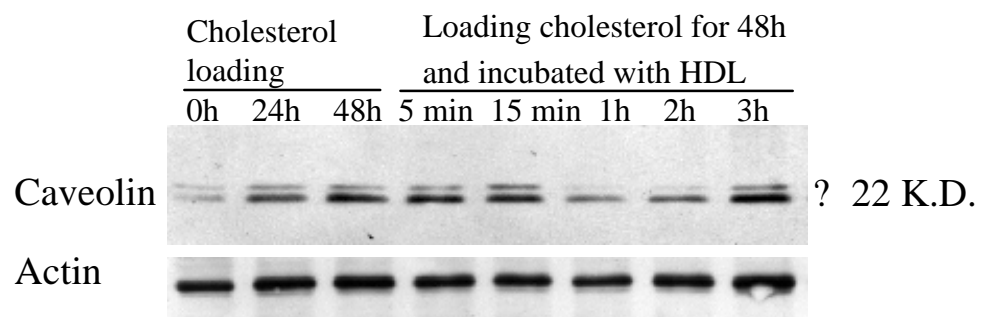

FIG. 3. The western blot analysis showed that when cells were incubated with cholesterol for 24, $48 \mathrm{hr}$, the expression of caveolin significantly increased. When cells were incubated with HDL, the expression of caveolin decreased at $1 \mathrm{~h}$, and increased again at $3 \mathrm{~h}$. 